\title{
Da forma urbana à cidade como informação
}

\author{
From urban form to the city as information
}

Vinicius M. Netto[a] (1)

[a] Universidade Federal Fluminense (UFF), Departamento de Urbanismo, Niterói, RJ, Brasil

Como citar: Netto, V. M. (2020). Da forma urbana à cidade como informação. urbe. Revista Brasileira de Gestão Urbana, 12, e20190242. https://doi.org/10.1590/2175-3369.012.e20190242

\section{Resumo}

0 presente artigo tem dois objetivos. Primeiro, traça um panorama inicial da pesquisa sobre forma urbana no Brasil e no Rio de Janeiro. Para tanto, discute algumas características das abordagens desenvolvidas nesse contexto bem como sinaliza possibilidades para o campo, incluindo expansões conceituais e metodológicas capazes de reconhecer as conexões entre forma urbana, cognição e dinâmicas sociais. Segundo, ilustra essas possibilidades com uma nova abordagem sobre a forma urbana como "informação". A abordagem explora os modos como preservamos informação no ambiente físico e semântico das cidades e como usamos essa informação ambiental para atuar e tomar decisões sobre ações e interações a realizar. Para entender o papel da informação ambiental na ação e cooperação social, a abordagem reúne modelos computacionais de cidades e comportamentos bem como medidas de informação e entropia latentes nas estruturas físicas e semânticas das cidades. Esses métodos permitem examinar cidades com grande grau de detalhe e interpretar diferenças entre ambientes urbanos como "assinaturas de informação" potencialmente consistentes com diferentes culturas espaciais. Finalmente, a abordagem permite avaliar o impacto de diferentes ambientes urbanos sobre ações e graus de cooperação entre as pessoas.

Palavras-chave: Forma urbana. Informação. Ambiente construído. Entropia. Cognição.

\section{Abstract}

This article has two aims. First, it provides an initial overview of research on urban form in Brazil and Rio de Janeiro. To this end, it discusses some characteristics of the approaches developed in this context, as well as indicating possibilities for the field, including conceptual and methodological expansions capable of recognizing the connections between urban form, cognition and social dynamics. Second, the article illustrates these possibilities with a new approach to urban form as "information". This approach explores the ways in which social agents preserve information in the physical and semantic environment of cities, and how they use this environmental information to act and make decisions about actions and interactions to be carried out. Thus, to understand the role of environmental information in social action and cooperation, the approach brings computational models of cities and behaviour, as well as information 
and entropy measures in the physical and semantic structures of cities. These measures make it possible to examine cities in great detail and to interpret differences between urban environments as "information signatures" potentially consistent with different spatial cultures. Finally, the approach makes it possible to assess the impact of different urban environments on actions and degrees of cooperation between agents.

Keywords: Urban form. Information. Built environment. Entropy. Cognition.

\section{Introdução: a investigação da forma urbana no Brasil}

Entre as diferentes tradições e focos da morfologia urbana, como aquelas estabelecidas a partir da escola Conzeniana sobretudo desde os anos 1950, seguida das escolas italiana e francesa, as que capturam de modo particular minha atenção vieram dos insights sobre topologia de Alexander (1965a, 1965b), do estudo analítico da forma construída na escola de Cambridge (Martin \& March, 1972), das análises da morfologia celular dos assentamentos e da rede de ruas de Hillier \& Hanson (1984) e das abordagens celulares da forma e a interação espacial de Batty (2005). Atentas à forma física das cidades, essas abordagens nunca me pareceram restritas a ela, estabelecendo conexões com aspectos sociais de diferentes temporalidades e escalas. Mesmo algo aparentemente objetivo como a forma urbana termina se revelando multidimensional, passível de ser percebido e abordado a partir de diferentes perspectivas, em diferentes aspectos, guiado por motivações e buscas (por conexões) distintas.

Seria útil termos uma genealogia ampla das ramificações dessas abordagens à forma urbana e dinâmicas sociais no Brasil - uma "pesquisa sobre pesquisa", algo que este artigo não pode fazer. Mas podemos adicionar esforços nesse sentido. Antes de tudo, é preciso dizer que esse corpus diverso de conhecimento parece encontrar interesse limitado no Brasil. Há evidências disso. Nosso levantamento recente em quatro dos principais veículos de publicação em estudos urbanos no país (Netto et al., 2020a), com um total de 3.897 artigos publicados entre 1999 e 2016, mostra que, entre 20 campos de pesquisa levantados, a morfologia urbana ocupa uma parte pequena da produção publicada em veículos expressivos em estudos urbanos no país, com menos de $2 \%$ dos artigos publicados na Revista Brasileira de Estudos Urbanos e Regionais (RBEUR) e de 4\% nos anais dos Encontros Nacionais da Associação Nacional de Pesquisa e Pós-graduação em Arquitetura e Urbanismo (ENANPARQ). Em que pese o fato de que o campo passou a contar com veículos em português nos anos 2010, notadamente a Revista de Morfologia Urbana e os encontros da Portuguese Network of Urban Morphology (PNUM), o peso da produção no contexto geral sugere um nicho com bordas relativamente limitadas.

Entretanto, o campo movimenta grupos de pesquisa envolvidos com aspectos diversos: a configuração particular da cidade brasileira (e.g. Holanda, 2002; Medeiros, 2013; Amorim et al., 2014); a lógica socioespacial de assentamentos, suas configurações específicas, incluindo assentamentos informais; reconstruções históricas da evolução de morfologias; análises da morfologia da rede de ruas em relação à copresença, movimento de pedestres, princípios de organização social e outros fatores de ocupação urbana, sobretudo em sintaxe espacial; as investigações da urbanidade; o desenvolvimento de ferramentas de análise espacial (Figueiredo \& Ortiz-Chao, 2015); a análise dos impactos da forma construída e da tipologia edilícia sobre a vitalidade, que chamamos "efeitos da arquitetura", e das condições da caminhabilidade e viagens a pé (Larrañaga et al., 2009); análises e interpretações tanto discursivas quanto quantitativas das associações entre forma urbana e sociabilidade, reprodução da violência, comportamentos espaciais, saúde pública e emissões de poluentes do ar; análises de desempenho urbano, dinâmicas de movimento do corpo e deriva (Aguiar, 2010) e, de modo crescente, das relações entre configuração e apropriação do espaço público, considerando ainda gênero e etnia.

O panorama do campo no Rio de Janeiro merece particular consideração. Parece haver poucos pesquisadores lidando assumidamente com morfologia urbana. Nesse contexto específico, o campo da morfologia urbana parece ser visto com certo ceticismo, supostamente por promover uma reificação da forma em desconexão com aspectos sociais mais profundos. Essa desconfiança latente merece ser examinada, porque é possível que uma ênfase descuidada na forma urbana de fato leve a desconexões com a riqueza de seus entrelaces na ação e experiência humanas. 0 caso ganha sentido particular no Rio 
de Janeiro por um simples motivo: em função de sua topografia singular, o Rio é atravessado pela realidade dura e evidente de sua pobreza praticamente onipresente - incluindo nos famosos bairros da zona sul. Nesse contexto a ideia de uma dialética socioespacial expressa em desigualdade extrema, frequentemente escondida nas periferias de outras cidades brasileiras, ganha apelo irresistível - e necessário - no Rio.

Dado que o desenvolvimento de abordagens de pesquisa envolve reduções analíticas de seus fenômenos de interesse, a questão sobre os limites e alcances da morfologia urbana como campo precisa ser endereçada explicitamente. Críticas de que "a forma não pode ser entendida isoladamente", mas seria "resultante do processo social" mostram desentendimento do campo e de procedimentos científicos de análise. A ideia de que a forma é resultante de processos sociais é autoevidente. Uma visão mais ampla da morfologia é a de um campo voltado para o entendimento de processos simultaneamente espaciais e sociais ou de espaços como parte da materialização do social, abordando inicialmente a partir do espaço. Nessa leitura, a forma é um objeto legítimo de análise - um caminho para entender suas propriedades e a materialidade inerente de processos e ações sociais. A análise da forma urbana pode revelar aspectos do social (veja Krafta, 2014, p. 10-11). Essa abordagem é absolutamente usual, por exemplo, em estudos arqueológicos de sociedades passadas, onde o "social" não está presente além de em suas materializações em artefatos e espaços.

Trabalhos em morfologia urbana frequentemente associam a forma espacial a aspectos da reprodução social. Essa é uma especificidade importante, porque a crítica ao campo parece vir sobretudo de abordagens focadas na produção do espaço e de estruturas sociais amplas - em processos de formação material que refletem e reforçam estruturas como as de classe ou que levem a fenômenos macroscópicos como a gentrificação. Sob o ponto de vista da longa temporalidade da formação dessas estruturas, as dinâmicas da reprodução no aqui e agora podem facilmente passar despercebidas. Ao envolverem a apropriação, movimento, copresença e interação dos corpos no espaço, essas dinâmicas incluem práticas e processos capturados, por exemplo, a partir de princípios Durkheimianos de coesão social baseados em similaridades e diferenças (Hillier \& Hanson, 1984) ou aspectos de habitus e estilos de vida, copresença e interação, ou via lógicas de comunicação, cooperação e conflito - dinâmicas que manifestam o "social" no aqui e no agora, mas, voláteis e elusivas, passam despercebidas para lentes focadas em macroestruturas.

Entretanto, a despeito dessas possibilidades, a "sociologia" de boa parte das abordagens em morfologia urbana é de fato limitada. Essas abordagens se beneficiariam se inseridas em visões mais ricas e complexas do mundo social e material, a partir do diálogo com diferentes disciplinas e áreas, da etnografia aos estudos sociotécnicos ou à teoria ator-rede.

A produção em morfologia urbana no Brasil se encontra em estágios diferentes de sistematização e precisão empírica. Nossa análise da produção de artigos no campo (Netto et al., 2020a) bem como minha experiência em andamento como editor da Revista de Morfologia Urbana permitem evocar algumas impressões sobre o campo no país:

1. Há um interesse crescente e bem-vindo na busca por evidências como formas de sustentação de argumentos. Entretanto, estudos empíricos frequentemente envolvem poucos casos selecionados, sem condição de oferecer confirmação ou rejeição de hipóteses ou representatividade frente ao problema, levando a um cenário de fragmentação metodológica e pouca robustez empírica;

2. Há necessidade de ampliar o diálogo não seletivo com o estado da arte dentro e fora do país. As referências utilizadas por autores são frequentemente mais centradas nos clássicos traduzidos do que no estado da arte, possivelmente em função de barreira linguística;

3. Há dificuldades na correspondência precisa entre a definição do problema de pesquisa, a definição do método e a especificidade dos achados empíricos que de fato esclarecerão o problema de pesquisa. A "hiperinflação" de afirmações e hipóteses sem devida ancoragem empírica se mostra frequente, sugerindo a necessidade de amadurecimento do campo em termos científicos; 
4. Podemos ver ainda uma limitação de ambição, com escassez de trabalhos propositivos em termos teóricos e metodológicos. Embora a presença de pesquisadores brasileiros em eventos no campo seja notável, sua contribuição efetiva tem sido limitada, como observam Pereira Costa \& Teixeira (2014).

\section{O que está à frente?}

Esses traços iniciais de um panorama do campo também sugerem possibilidades. A frente mais evidente para novas pesquisas vem do enorme potencial de análise da forma urbana emergindo a partir de recursos digitais - uma data-driven urban morphology amparada pela ciência de dados, ciência de redes e geometria computacional (Boeing, 2019). Novos caminhos de pesquisa vêm se abrindo com a geração de dados em tempo real a partir de smartphones entre outros dispositivos móveis e sensores instalados no tecido urbano, permitindo exames detalhados de comportamentos espaciais individuais. Essas tecnologias ainda permitem conhecer padrões coletivos e dinâmicos - como comportamentos de viagem, mobilidade e recursividade de atividades, fatores de saúde pública e segurança, e dinâmicas de localização e transformação urbana (Evans-Cowley \& Griffin, 2012). Permitem ainda explorar a relação entre forma urbana e comportamentos dos cidadãos alimentados em plataformas digitais de participação social, dando suporte a abordagens de planejamento baseadas em evidências e dados e as tecnologias promovidas pelas smart cities (Angelo \& Vormann, 2018; Kitchin, 2016).

Pesquisadores vão ganhar liberdade teórica ao explorar aspectos cada vez mais sutis e sistêmicos da forma e do urbano, como as abordagens celulares e fractais consolidadas desde os anos 1970 até a nova ciência de redes sugerem. Ganharão poder explicativo ao explorarem novos recursos metodológicos, como o desenvolvimento de algoritmos para análise e simulação. Em outras palavras, o campo está se movendo para além de análises meramente iconográficas da forma urbana e de análises de acessibilidade topológica via ferramentas pré-prontas. Usando linguagens de programação como Python e $R$, pesquisadores vão cada vez mais desenvolver suas próprias ferramentas, calibradas para capturar aspectos específicos de seus fenômenos de interesse.

Isso sugere que o campo da morfologia urbana vai se expandir e se conectar mais e mais a outros, como pesquisas sobre redes espaciais e sociais, assim como mobilidades e transformação espacial próximas ao tempo real e às qualidades relacionais do espaço urbano e do social. Um exemplo dessa possibilidade é entender como cidades se relacionam a outros sistemas complexos. Pesquisadores têm investigado vários aspectos desse jogo, como as conexões a sistemas ecológicos ou biofísicos no metabolismo urbano (veja Binder et al., 2020). Meu interesse atual envolve as relações entre cidades, nossa cognição e nossas ações sociais em uma visão do espaço urbano como "informação espacial".

\section{Informação: conectando mentes, cidades e sociedade}

A ideia da "informação" capturou nossa imaginação: a crescente profusão de meios de comunicação e dados, o aumento da capacidade computacional, a impressão de que estamos de algum modo imersos em informação. Da física às ciências sociais, a informação é hoje vista como um componente fundamental da realidade (Davies \& Gregersen, 2010; Hidalgo, 2015). No entanto, uma forma de informação parece subestimada, talvez precisamente porque é tão presente: a informação codificada no próprio ambiente em que vivemos. Ainda não entendemos como a informação toma a forma de cidades e como as nossas mentes lidam com ela para aprender sobre o mundo, tomar decisões cotidianas, construir nossos relacionamentos sociais e participar dos complexos sistemas de interação que criamos inconscientemente enquanto vivemos coletivamente. Ainda não entendemos inteiramente como a cognição e o impulso humano à interação moldam nosso ambiente e como o ambiente molda nossas mentes e interações em retorno. Esse desconhecimento é sentido em diferentes disciplinas, da neurociência à arquitetura (veja Ekstrom et al., 2018). 
Embora nossas mentes, cidades e sociedades sejam sistemas complexos individualmente, esses sistemas se relacionam entre si (Figura 1). Trabalhando juntos, eles de alguma forma criam um único sistema interativo.

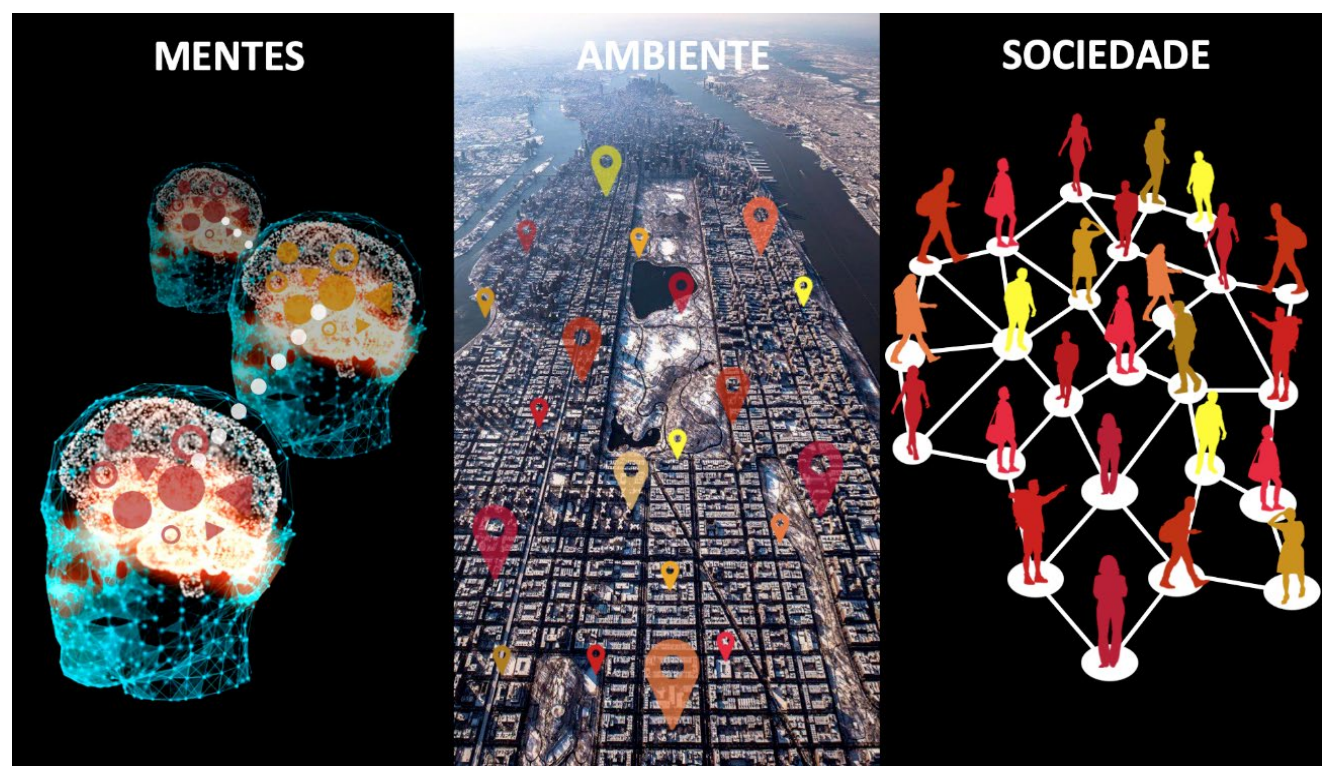

Figura 1 - Sistemas complexos se relacionam e interligam em um único sistema interativo. Fonte: Vinicius M. Netto e Vinicius Aleixo.

Reunirei neste artigo as proposições e achados iniciais sobre essas relações desenvolvidos em meu trabalho junto a um grupo de pesquisadores que inclui os físicos Edgardo Brigatti e Fabiano L. Ribeiro, o pesquisador em complexidade João Meirelles, o urbanista Caio Cacholas e o programador Lucas Martello, entre outros (Netto et al., 2017, 2018, 2020b, 2020c). Nesses estudos, nossa proposição inicial foi a de que essa integração improvável só poderia acontecer por meio de uma ponte que possa conectar esses diferentes sistemas - algo que mentes, cidades e sociedades tenham em comum: a informação. Esses sistemas dependem dela. Mentes processam informação. Sociedades trocam informação para existir. 0 ambiente pode ser moldado em estruturas carregadas de informação. Esses sistemas processam, compartilham e preservam informação. Seria informação a ponte?

Tentamos entender o papel da cidade como ambiente de informação para a interação, vida $e$ organização social. Isso se relaciona aos modos como usamos o ambiente urbano para conhecer oportunidades de interação, acessá-las e conectar nossas ações, construindo aos poucos, do micro para o macro, os sistemas de interação que viabilizam nossa sociedade. Nossa hipótese inicial é a de que o espaço urbano incorpora informação, que nós, humanos, somos capazes de ler e decodificar. Essa informação ambiental afetaria nossas ações e o modo como vivemos juntos e cooperamos. Investigamos cidades como um meio para criar esses sistemas de informação e cooperação.

Nossas inferências vão mais longe. Propomos que, ao ganhar estrutura, o espaço urbano facilita nossos esforços para entender nosso ambiente e navegar nele, reduzindo incertezas que poderiam dificultar nossas ações e interações. A informação impressa no ambiente construído estimularia as pessoas a conhecer e acessar oportunidades de atividades, as pessoas e instituições disponíveis em seu contexto e as interações mais úteis ou de maior interesse individualmente e para o todo, coletivamente. Assim, o espaço urbano seria um meio para coordenarmos um número enorme de ações e decisões pessoais aparentemente caóticas. Uma hipótese mais arrojada é a de que cidades se tornariam um recurso fundamental ao ponto de humanos codificarem informação no ambiente construído de modo a facilitar sua cooperação. Essa última hipótese é mais difícil de demonstrar empiricamente e ficará fora do escopo desta abordagem.

Esse papel extraordinário tem sido reduzido a uma visão de cidades e de "informação espacial" como fontes de dados e infraestrutura tecnológica no debate das smart cities. Cidades são muito mais do que isso. Elas são vastos complexos de informação que estimulam nosso conhecimento e interação. Desde Jacobs (1969) sabemos que nossas interações se beneficiam de ambientes densos e bem distribuídos. A informação urbana tem a ver 
com o quanto o ambiente de cidades e bairros dá suporte a seus habitantes: o quanto oferece de orientação e acesso a atividades, catalisando interações. A informação ambiental é parte de como aprendemos sobre o mundo, sobre as pessoas que comporão nossas redes sociais e sobre as atividades disponíveis ao nosso redor.

Essa questão também tem a ver com a distribuição de oportunidades à população de uma cidade. É provável que a informação ambiental seja distribuída de forma desigual entre áreas e cidades diferentes. Cidades que permitem às pessoas conhecer oportunidades, acessá-las de maneira mais eficiente, interagir de forma mais diversa e cooperar mais amplamente tenderiam a ser cidades mais justas. 0 acesso à informação ambiental se mostra um fator de justiça socioespacial — um fator sutil, mas potencialmente determinante em nossas ações.

Essas são as hipóteses. Nossa pesquisa tem criado ferramentas para analisar esse papel das cidades como meios informacionais importantes para entender como a informação ambiental se torna disponível e distribuída a seus habitantes. Reunindo teoria da informação, ciência cognitiva, estudos urbanos e teoria social e ecoando a definição clássica de Warren Weaver (1949) do problema da comunicação, examinamos três questões que precisam ser respondidas se quisermos entender como a informação impressa no ambiente construído dá suporte a nossas ações:

1. Como imprimimos e preservamos informação no ambiente? (0 problema físico);

2. Como damos significado à informação ambiental? (O problema semântico);

3. Como usamos a informação ambiental em nossas ações? (O problema prático).

Buscando uma solução para esses problemas, introduzimos um modelo teórico de três camadas de informação nas cidades (veja Netto et al., 2018). A informação 1 ou informação física é de alguma forma incorporada em arranjos espaciais tangíveis. A segunda camada, informação 2, semântica, se superpõe à camada 1 e inclui os conteúdos significativos que não estão impressos na estrutura física, mas que criamos em lugares com nossas práticas e atividades sociais. Essas duas camadas compõem a informação ambiental ao nosso redor, usada para instruir nossa cognição e nossas ações (cf. Vygotsky, 1978; Wilson, 2002). A terceira camada, informação 3 ou informação prática, é a que criamos em nossas mentes e trocamos em nossa comunicação, decodificando informação 1 e 2 do ambiente, compondo nossas percepções e apoiando nossas interpretações, decisões e ações cotidianas (Figura 2).

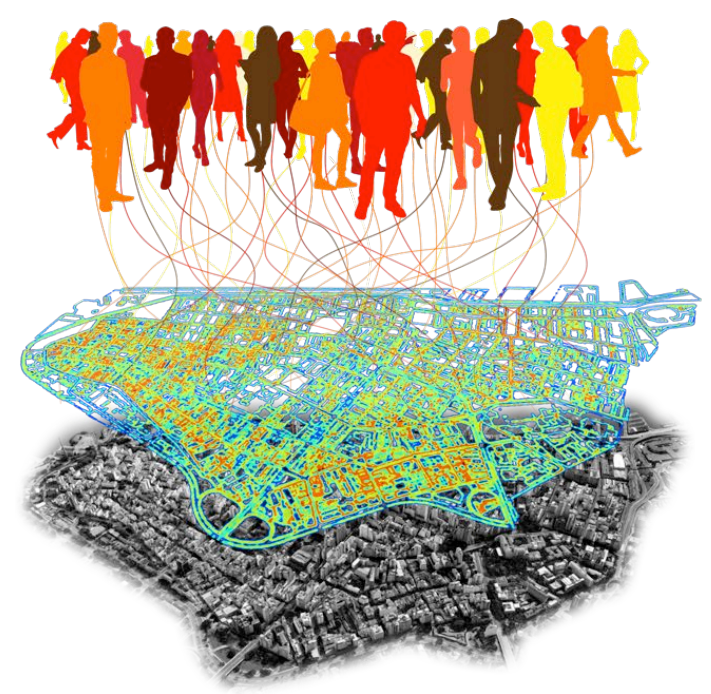

Informação 3 | prática

Prática: ações e interações.

Selecionar e ir a lugares.

Comunicação e cooperação.

Informação 2 | semântica

Espaço semântico.

Conteúdos sociais no espaço

suportam nossas ações.

\section{Informação 1 | física}

Espaço físico:

Ruas e edifícios.

Marcos visuais.
Conexão combinatória de ações.
Distribuição de atividades. Diversidade. Complementaridade.

Niveis de ordem. Estrutura e hierarquia.

Figura 2 - Camadas de informação: informação 1 (ambiente físico), informação 2 (ambiente semântico) e informação 3 (prática), seus componentes e propriedades empíricas. Fonte: Vinicius M. Netto e Caio Cacholas em Netto et al. (2018). 
Teorias clássicas em estudos espaciais e cognitivos lidam com essas formas de informação até diferentes pontos. Por exemplo, a "imagem da cidade" de Lynch (1960) trata da informação física ao lidar com estruturas urbanas, cognição e navegação, também quando a forma urbana adquire valor visual referencial. A sintaxe espacial de Hillier \& Hanson (1984) relaciona informação física a aspectos elementares da prática, identificando padrões nas redes de ruas relacionados à nossa cognição, movimento e copresença no espaço. Por sua vez, as recentes redes sinergéticas de inter-representação do físico Hermann Haken e do geógrafo cognitivo Juval Portugali (Haken \& Portugali, 2015) operam principalmente nas duas primeiras camadas, unindo informação em objetos visuais e informação semântica, mas ainda sem relação com o surgimento de sistemas de interação e cooperação, mediados pela informação 3 .

Essa é uma questão de interesse também se pensarmos nos crescentes desafios enfrentados pelas sociedades contemporâneas, como o problema da redução de consumo de materiais e externalidades de processos produtivos e urbanos ou como o severo problema de saúde pública da pandemia enfrentada em 2020. É provável que as soluções para esses desafios exijam novos e impressionantes níveis de coordenação: precisaremos mudar comportamentos, de modo que nossas ações convirjam para direções sustentáveis (Netto et al., 2020b). A necessidade de cooperação e coordenação de ações passa a ser central. Para um sistema seguir em frente, precisa evoluir para estados nos quais a coordenação é viável. Os desafios mencionados podem ser esclarecidos por um conceito clássico: entropia. Entropia é uma medida de incerteza (Shannon, 1948) e de desordem (Prigogine \& Stengers, 1984). Nossas ações individuais são atravessadas por incertezas, das escolhas diárias que fazemos às consequências não intencionadas de nossas ações. Se a entropia se relaciona com incerteza e desordem e se sociedades enfrentam entropia o tempo todo, a continuidade de sociedades problema é dificultada. 0 conceito de entropia permite que entendamos desde as consequências coletivas das decisões que tomamos diariamente a estados como crises públicas e urbanas.

Nossa sociedade exige uma alta capacidade para acessar informação e recombinar ações em cooperação entre pessoas, grupos e instituições. São sistemas "famintos por informação". Essa dependência requer diferentes tipos de informação. Nesse cenário, a informação ambiental pode desempenhar um papel chave. A possibilidade de as cidades poderem preservar informação em seus espaços daria suporte às pessoas nas suas interações e contrabalançaria tendências à fragmentação e entropia.

\section{Definições de informação}

Há muitas ideias distintas sobre o que é informação. Nos primórdios da computação, o engenheiro de comunicação Claude Shannon (1948) estabeleceu uma definição clássica sobre informação contida em sinais transmissíveis por cabos: dados bem estruturados na forma de mensagens. Adiante, o antropólogo Gregory Bateson (1972) definiu informação como "diferença" — ou mais precisamente, "uma diferença que faz diferença": a unidade elementar de informação é baseada em distinções entre as coisas. Por sua vez, o filósofo Fred Dretske (1981) foca na informação semântica como dados bem estruturados e com significados. Há ainda leituras de informação em coisas tangíveis: o genial físico Erwin Schrödinger (1944) via informação em coisas contendo "correlações internas" dentro de suas estruturas, uma ideia de informação como ordem preservada em forma sólida explorada recentemente por César Hidalgo (2015).

Mas ambiente construído poderia realmente preservar informação? Como vimos, essa ideia não é nova na teoria urbana. Ela está presente nos elementos espaciais de Lynch (1960), orientando nosso senso de navegação no ambiente, junto com nossa memória e representações da cidade, embora Lynch não tenha explorado o termo "informação". Rapoport (1982, p. 19) afirmou explicitamente que "[...] elementos físicos do ambiente codificam informações que as pessoas decodificam". Haken \& Portugali (2015) viram informação latente nos layouts de ruas e na forma construída. De fato, seria interessante se a informação pudesse ser codificada em estruturas físicas. A informação dura mais quando preservada em entidades tangíveis 
(Hidalgo, 2015). Se o espaço físico também fosse capaz de materializar informação, teríamos uma forma de codificar informação no próprio ambiente construído, podendo decodificá-la enquanto vivêssemos nele. Uma forma de informação materializada no ambiente construído abriria possibilidades cognitivas e práticas extraordinárias.

Essa ideia encontra suporte crescente na literatura: (i) a cognição é vista como situada, moldada por sua contínua interação com o ambiente (Vygotsky, 1978; Varela et al., 1991; Clark \& Chalmers, 1998); (ii) carregamos o ambiente construído com informação, através de associações entre aspectos do ambiente e significados socialmente compartilhados (Rosch, 1978; Passini, 1992); (iii) a informação ambiental aliviaria nosso trabalho cognitivo, porque nosso conhecimento integra aspectos visuais, configuracionais e semânticos projetados no ambiente como representações e extensão de nossas memórias (Wilson, 2002); (iv) nossa cognição é pressionada pelo tempo e por nossa ação, estimulando a ampliação de nossa capacidade cognitiva a partir da interação e formação de modelos mentais de nosso ambiente (Clark, 1997); e, finalmente, (v) construímos instruções sobre eventos a partir do ambiente, apoiando nossos planos de ação de forma adaptativa. A informação ambiental serve nossa ação (cf. Wilson, 2002).

Essas são proposições sobre como nossas mentes se estendem em nossos ambientes e são fortes hoje na ciência cognitiva e na neurociência, como veremos. Entretanto, ainda precisamos entender como criamos e preservamos informação no ambiente e, sobretudo, como usamos essa informação ambiental para cooperar e construir mundos sociais.

\section{Circuitos de informação: do ambiente à interação}

Como a informação conecta mentes, cidades e sociedades em um único sistema? 0 ambiente que criamos é composto por estruturas tangíveis e não tangíveis, uma interação de arranjos físicos (informação 1) e configurações de significado de lugares e práticas no espaço urbano (informação 2). Os agentes codificam e decodificam informações no ambiente conforme se relacionam a ele via nossa percepção e cognição situada. Por sua vez, a cognição emerge de processos distribuídos, uma operação coletiva produzida por interações entre agentes em relação ativa com o ambiente (Figura 3).

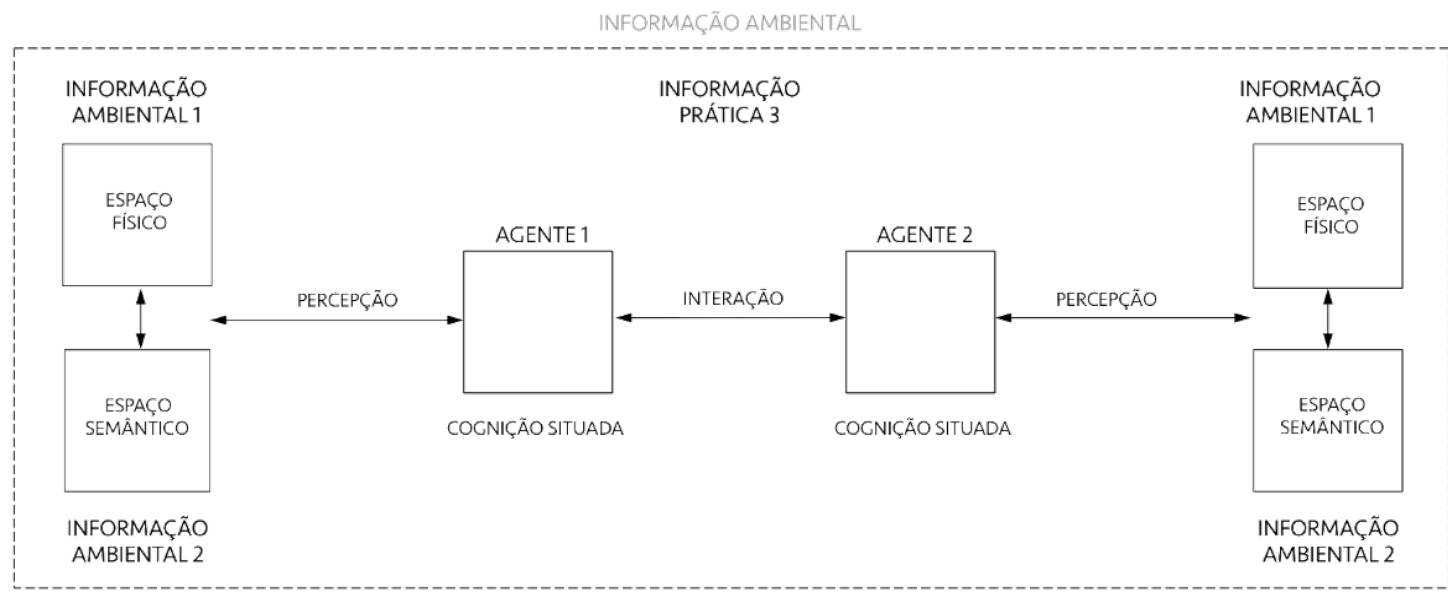

Figura 3 - Diagrama de um sistema de informação-interação. Fonte: Netto et al. (2018).

As possibilidades de ação individual dependem da informação ambiental e da distribuição das ações realizadas pelos agentes. Os agentes desenvolvem suas capacidades cognitivas criando o ambiente no qual as exercem (Hutchins, 1995). A cognição se estende ao ambiente: os agentes trocam informações com o ambiente enquanto regulam as condições dessa troca. A cognição também se estende à interação: os agentes interagem dependendo fisicamente e cognitivamente de seu ambiente. Essa extensão da 
percepção ao ambiente e à coordenação de ações é a definição de enaction ou "enação" (Varela et al., 1991), o que chamarei de "informação 3".

Esses fatores todos estão imersos em um jogo de relações. Entrar nesse jogo nos leva a algumas perguntas: como as informações ambientais 1 e 2 podem nos ajudar a interagir e conectar nossas ações? Muitas de nossas ações em uma cidade envolvem escolher atividades e interações dentre um número enorme de possibilidades. Como o ambiente construído afeta esse conhecimento, seleção e decisão sobre que possibilidades seguir em nossas ações e interações? Respostas a essas e outras questões demandam uma série de passos metodológicos envolvendo cada uma das camadas de informação propostas.

\section{Informação 1: o espaço físico}

Desde o trabalho pioneiro de Shannon (1948) na teoria matemática da comunicação, a definição de informação está associada à construção de mensagens a partir de uma linguagem focada no dimensionamento de canais de comunicação capazes de lidar com qualquer combinação de signos. Shannon propôs que o número de mensagens possíveis a serem transmitidas pode explicar a quantidade de informação neles embutida, equalizando "informação" e "entropia". Entretanto, na tradição na física desde Boltzmann (2015) em 1877, a entropia está associada à desordem (Prigogine \& Stengers, 1984). Arranjos com maior entropia são caracterizados por níveis mais altos de aleatoriedade, imprevisibilidade e incerteza. Por sua vez, níveis de previsibilidade estão associados à ordem. Estruturas ordenadas contêm correlações como semelhanças, consistências e associações que são a "substância" da informação (Hidalgo, 2015). Nesta visão, a informação é o padrão de organização (Parker, 1974) - por exemplo, como regularidades em um arranjo físico ou um padrão de distribuição de atividades tomando a forma de um centro urbano. Informação está assim ligada à inteligibilidade e ordem em objetos e estruturas.

Esta definição faz sentido sob o ponto de vista da informação ambiental. A pesquisa em informação espacial tem focado principalmente em como decodificamos informações do ambiente construído - por exemplo, o papel da percepção e entidades visuais na navegação e na tomada de decisão espacial (e.g. Caduff \& Timpf, 2008; Garlandini \& Fabrikant, 2009). Mas como humanos codificariam informação no ambiente construído? Neste momento, não temos resposta a essa pergunta. Trabalhos em neurociência confirmam que a memória de um ambiente pode ser armazenada como uma combinação de posições que disparam reações neurais, marcando essas posições na medida em que navegamos no espaço, formando um mapa mental do ambiente espacial organizado topologicamente. "Células-grade" no cérebro são ativadas sempre que nossa posição coincide com vértices de uma grade hexagonal regular que cobre o ambiente em nossas representações mentais, como o trabalho de John O'Keefe, Edvard e May-Britt Moser, premiados com o Nobel de Medicina em 2014, confirmou (O'Keefe \& Dostrovsky, 1971; Hafting et al., 2005). As células-grade são críticas para a navegação baseada em vetores, sendo combinadas com estratégias baseadas em caminhos para dar suporte à navegação em ambientes desafiadores (Doeller et al., 2010). Entretanto, ainda que a pesquisa da conexão desses disparos em humanos em relação a estruturas urbanas reais esteja em seu início (Bellmund et al., 2016), já sabemos que regularidade, paralelismos e previsibilidade no ambiente construído são úteis para ancorar nosso sistema interno de navegação (Banino et al., 2018; Ekstrom et al., 2018).

Cidades têm diferentes estruturas e níveis de regularidade. Como podemos entender essas estruturas físicas sob a luz da informação ambiental? Propomos capturar níveis de informação 1 reconhecendo frequências de objetos espaciais (digamos, edifícios) no ambiente. Por exemplo, arranjos regulares podem permitir inferências sobre áreas além das que podemos ver em certo momento. Se esse for o caso, quanto maior a variação nos eventos no ambiente, menos encontraremos consistências que nos permitam entender o todo e fazer inferências sobre sua estrutura mais ampla. Essas são questões de pesquisa ainda abertas, mas os trabalhos recentes em 
neurociência citados acima fornecem indícios de interesse. No nosso caso, investigamos se as pessoas leem informação no espaço físico ao perceber arranjos ordenados. Para tanto, analisamos com Edgardo Brigatti e Caio Cacholas alguns dos constituintes mais profundos da forma construída: as agregações edificadas, reduzidas a arranjos celulares em um espaço bidimensional (Figura 4). Naturalmente, o ambiente construído codifica mais informação do que configurações bidimensionais podem expressar. No entanto, optamos por uma abordagem analítica capaz de descrever mínima e suficientemente as diferenças nas informações potencialmente codificadas na forma urbana construída - daí nossa redução da forma urbana para agregações celulares. Esta abordagem analisa ainda se certos arranjos conteriam mais informação física, para então avaliálos empiricamente.
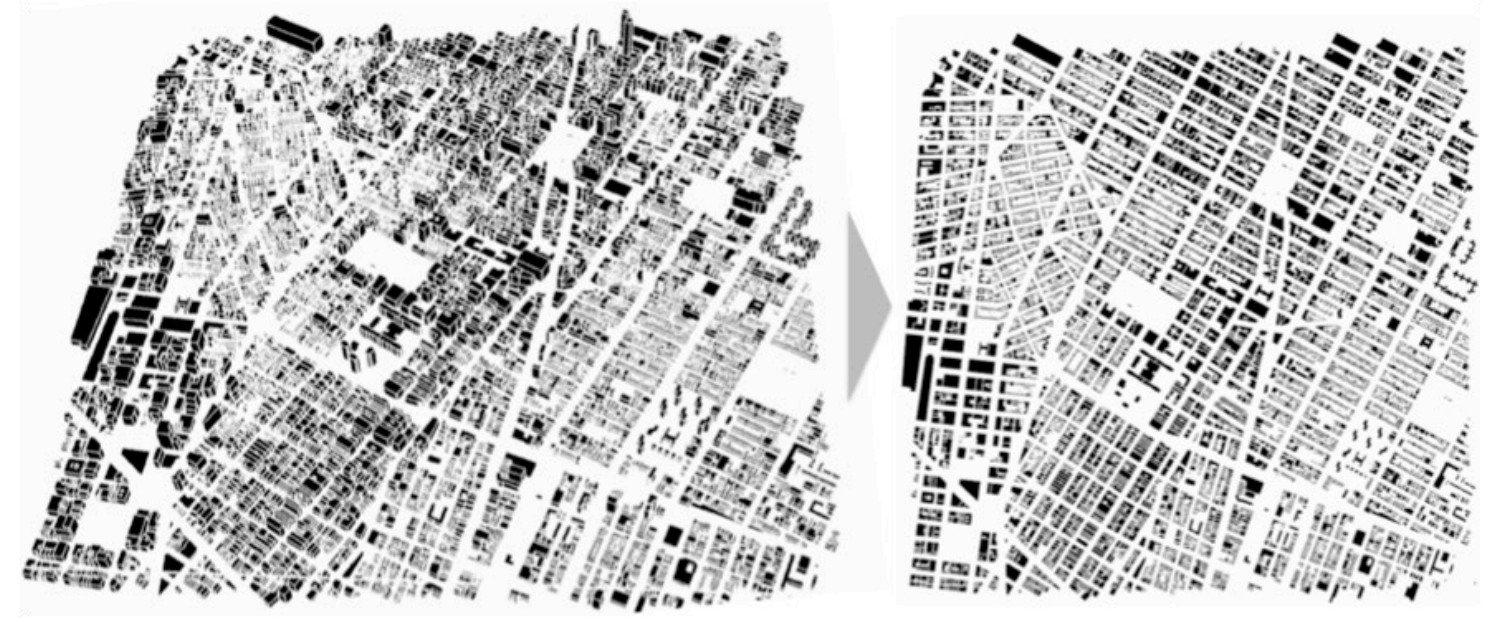

Figura 4 - Redução da forma tridimensional a arranjos bidimensionais, em tese capazes de manter características estruturais (Manhattan). Fonte: Caio Cacholas em Netto et al. (2020c).

Abordagens à informação espacial usualmente adotam medidas de densidade de informação e entropia para avaliar a redundância relacionada aos esforços cognitivos para extrair informação relevante desses ambientes (e.g. Rosenholtz et al., 2007). Nesta abordagem, exploramos tal possibilidade analisando os níveis de previsibilidade em arranjos físicos usando conceitos estatísticos. Essa definição, entretanto, não esgota as possibilidades de relação entre informação ambiental e estruturas espaciais: "diferença" e "estrutura" são aspectos ainda fora do seu alcance metodológico. Por ora, a medida de informação 1 é capaz de compreender regularidades e variações em configurações reais, mesmo em tradições urbanas completamente diferentes. Para avaliar isso, usamos a medida de entropia de Shannon. Como vimos, a presença de regularidades, estruturas e padrões corresponde a níveis mais baixos de entropia, o que é consistente com a visão de entropia na física (veja Prigogine \& Stengers, 1984). Já altos níveis de entropia correspondem a altos níveis de aleatoriedade ou imprevisibilidade em um sistema (Figura 5).
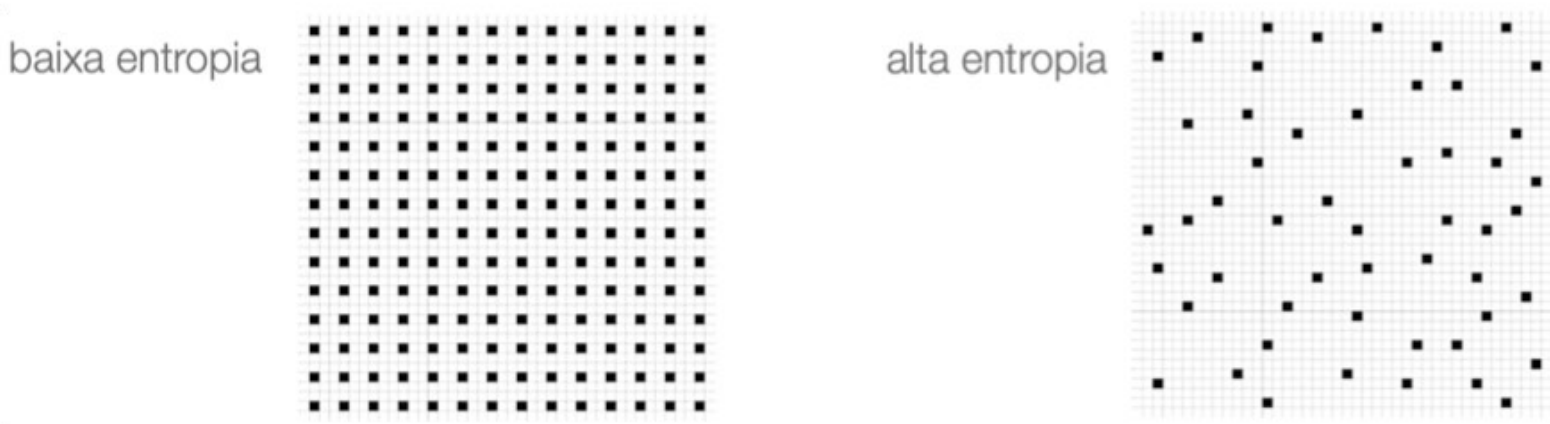

Figura 5 - Arranjo celular de alta regularidade e previsibilidade (à esquerda) e arranjo de alta irregularidade e imprevisibilidade (à direita). Fonte: João Meirelles e Caio Cacholas. 
A medida de entropia explorada por Brigatti captura variações sutis em configurações urbanas e caracterizar diferentes cidades e áreas urbanas. Para tanto, desenvolvemos e aplicamos a medida em amostras de áreas geográficas extraídas de repositórios de mapas públicos como o Google Maps. Essas imagens passam por um processo de conversão em um sistema monocromático e por um recorte em janelas de 10002 pixels de $3 \times 3$ metros ou $9.000 .000 \mathrm{~m} 2$, sendo então traduzidas em uma matriz de valores binários representando células edificadas e livres para a análise dos arranjos de células em cada janela.

A análise estima as probabilidades de encontrarmos arranjos diferentes de células a partir da contagem da frequência de cada arranjo presente nas estruturas reais (Figura 6). Por exemplo, a cidade do Rio de janeiro (esquerda) mostra uma grande variação de arranjos do tipo (a). Isso significa baixa frequência de arranjos repetidos e alta imprevisibilidade e entropia nos arranjos. Por sua vez, arranjos do tipo (b) são frequentemente encontrados em Manhattan (direita). A alta frequência das mesmas configurações aproxima a medida de entropia de 0 , ou seja, Manhattan mostra níveis altos de ordem física e, portanto, de informação 1.
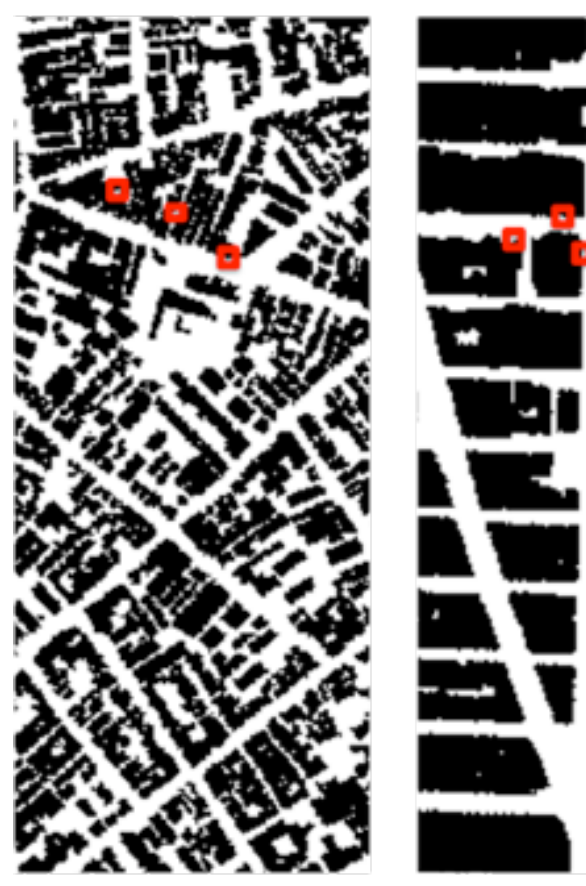

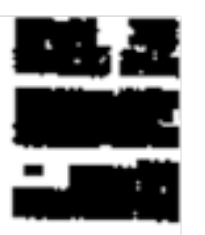

a.
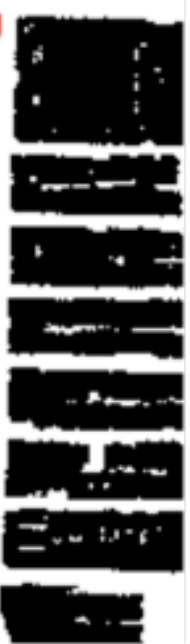

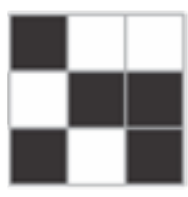

b.
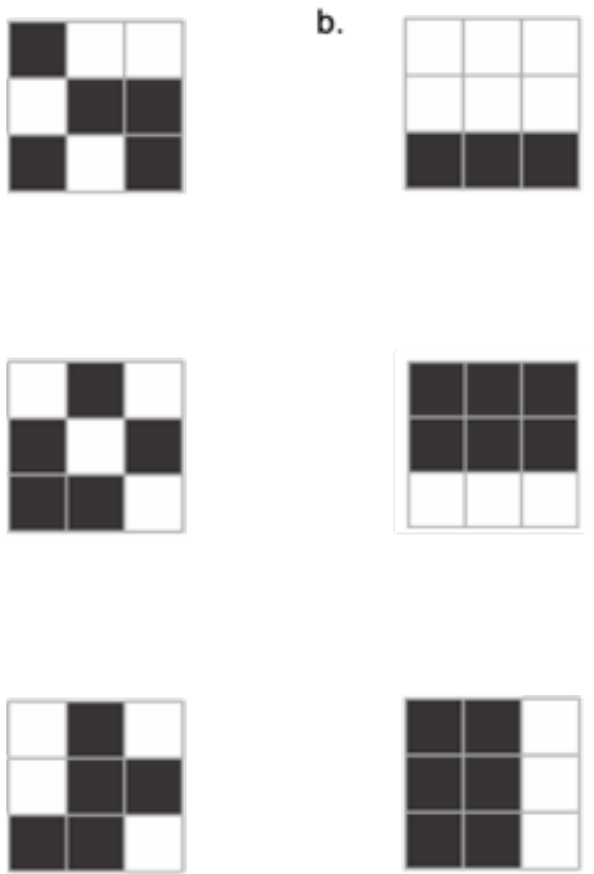

Figura 6 - Avaliando a frequência de arranjos celulares como medida de entropia. Exemplos de blocos de nove células são mostrados em vermelho para áreas selecionadas no Rio e Manhattan (à esquerda) e amplificados à direita. O Rio mostra uma grande variação de configurações do tipo (a) indicando muitas formações irregulares,

baixa previsibilidade e alta entropia. Configurações do tipo (b) são bastante frequentes em Manhattan, contendo maior número de formações regulares, alta previsibilidade e baixa entropia. Fonte: Vinicius M. Netto e Caio Cacholas em Netto et al. (2020c). 

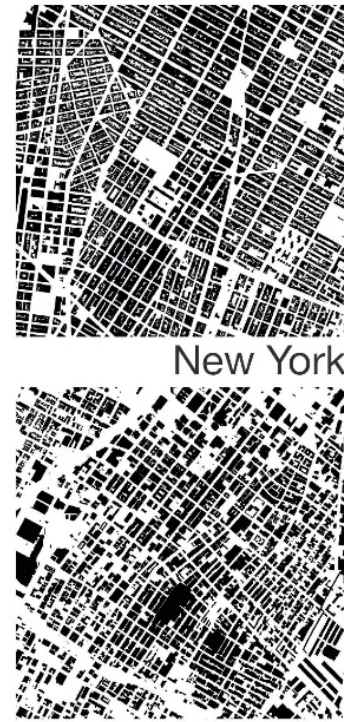

Los Angeles

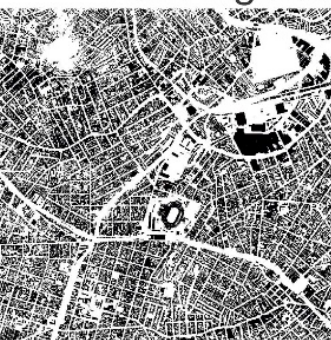

Rio de Janeiro

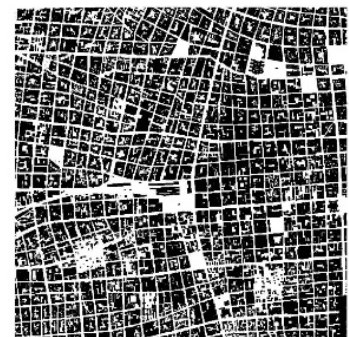

Buenos Aires

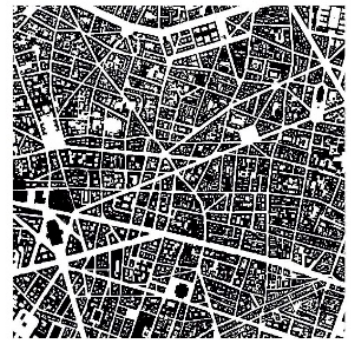

Paris

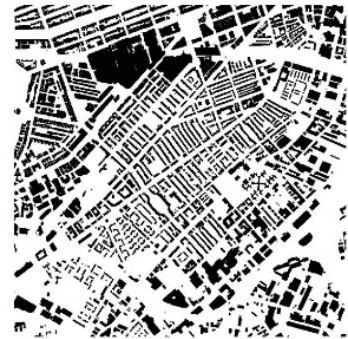

Boston

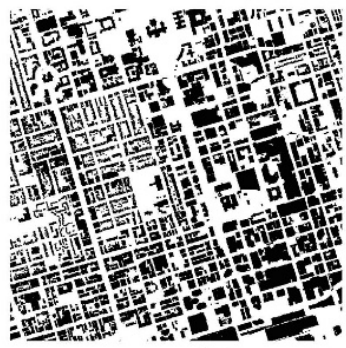

Toronto

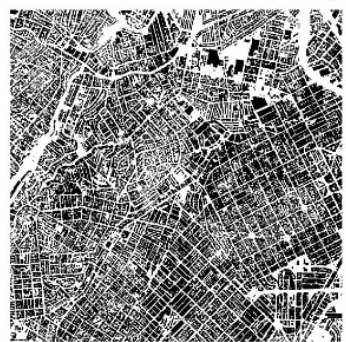

São Paulo

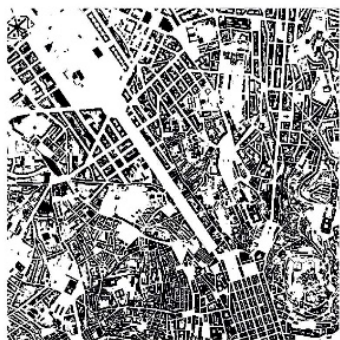

Lisbon

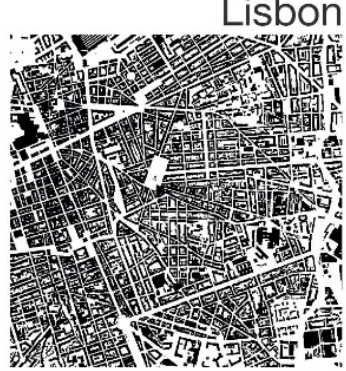

Marseille

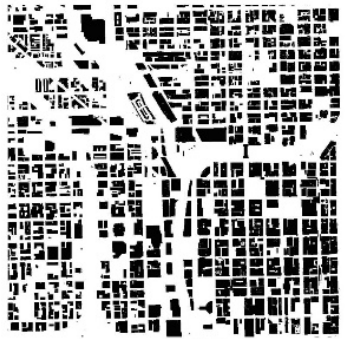

Chicago

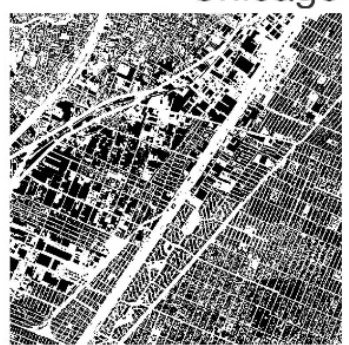

Ecatepec

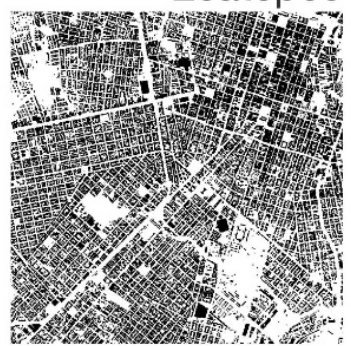

Fortaleza

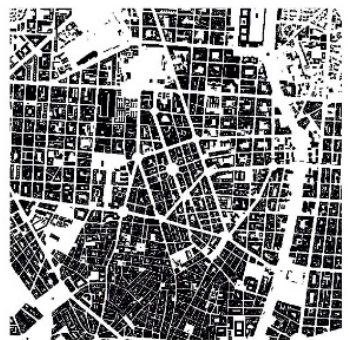

Madrid

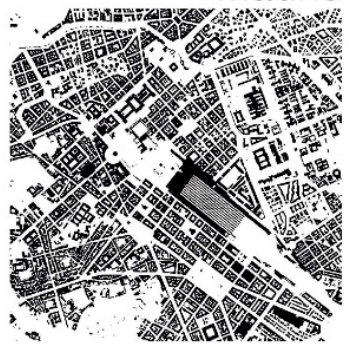

Rome

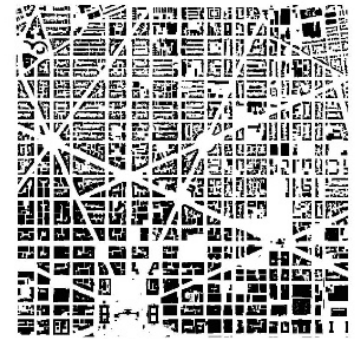

Washington

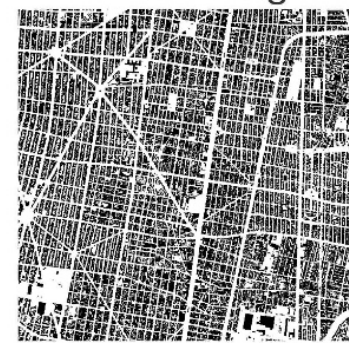

Mexico City

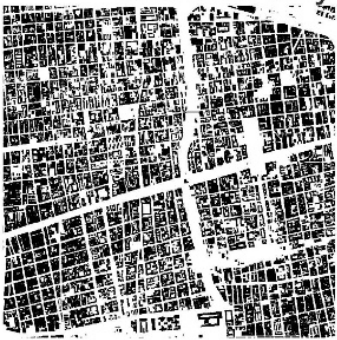

Santiago

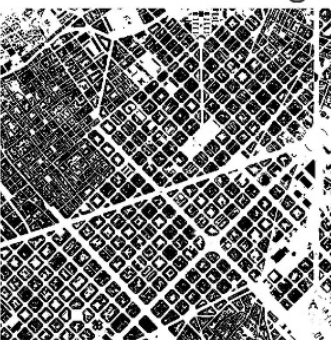

Barcelona

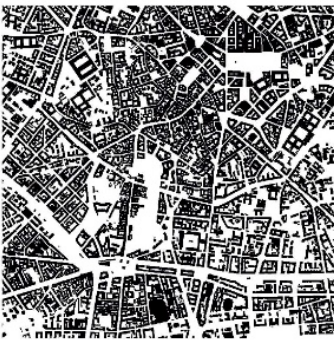

Milan

Figura 7 - Distribuições físicas em vinte cidades reais (janelas de $9 \mathrm{~km}^{2}, 1000^{2}$ células), usadas para estimar a entropia de Shannon e graus de desordem nos arranjos espaciais. Fonte: Vinicius Aleixo e Caio Cacholas em Netto et al. (2019).

Em nosso trabalho com Brigatti e Cacholas, estimamos a entropia de áreas de dezenas de cidades selecionadas (Figura 7) a partir da fórmula de Shannon ${ }^{1}$. Cidades brasileiras mostraram o maior nível de entropia nos seus arranjos de edificações, contendo menor grau de informação 1 (Figura 8, à esquerda).

\footnotetext{
${ }^{1}$ Veja o desenvolvimento das equações de entropia derivadas de Shannon em Netto et al. (2018; 2020c).
} 
Por sua vez, cidades americanas mostraram alto grau de informação 1 - um achado confirmado em nosso estudo em 45 cidades de diferentes regiões do mundo (Netto et al., 2020c). Essa medida mostra potencial para identificar "assinaturas de informação" de cidades de diferentes culturas espaciais, o que permitiria testarmos a hipótese da existência de características regionais consistentes na morfogênese urbana. Diferenças entre cidades e culturas urbanas ficam visíveis nos clusters formados a partir da análise da proximidade nos seus níveis de informação 1 (Figura 8, à direita) (veja Netto et al., 2019).

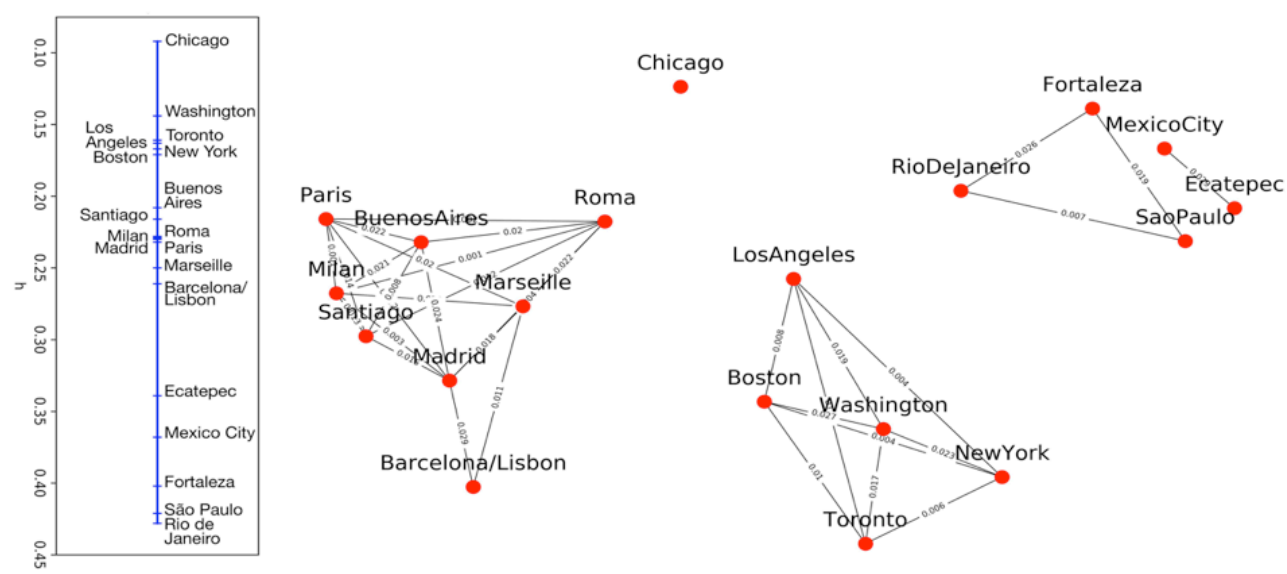

Figura 8 - Medida de informação ambiental 1. Valores estimados de entropia (h) para vinte cidades de diferentes regiões do mundo (esquerda). A rede de proximidade (direita) mostra cidades mais similares em valores de entropia com graus indicados nas linhas. Fonte: Edgardo Brigatti em Netto et al. (2019).

Até aqui, a abordagem levou em conta apenas a informação em estruturas bidimensionais. Suas conexões com a tridimensionalidade, referências visuais e seus efeitos informacionais serão objeto do desdobramento da abordagem.

\section{Informação 2: o espaço semântico}

A segunda camada de informação se refere ao modo como o ambiente adquire significados e interpretações para as pessoas. Há um grande aumento no potencial informacional quando consideramos essa informação semântica. A diferença entre a informação ambiental 1 e 2 é análoga à diferença entre uma imagem em preto e branco e uma imagem colorida. À medida que cada cor encontra sua própria paleta de tons, as cores trazem muito mais diversidade, levando a um enorme aumento nas possibilidades combinatórias entre entidades (Figura 9).
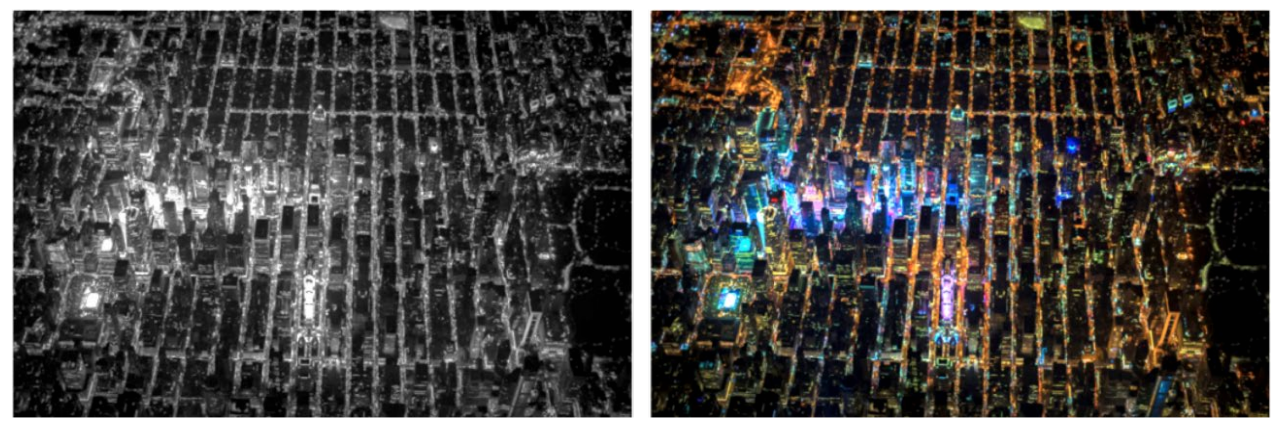

Figura 9 - As cores encontram sua própria paleta de tons, tornando-se mais diversificadas e contrastantes na passagem das escalas cinza para as coloridas, levando a uma explosão combinatória. Foto: Vincent Laforet.

Estudos em informação espacial têm visto associações entre características físicas e conteúdos semânticos nas cidades. Processos cognitivos desencadeiam associações com elementos do ambiente por meio da incorporação de informações socialmente adquiridas, compartilhadas (Passini, 1992; Taylor et al., 2011) e classificadas em categorias (Rosch, 1978; Devlin, 1991). Informações não espaciais podem ser integradas a 
informações espaciais (McNamara et al., 1992), dado que processos de agrupamento categórico semântico se relacionam a características espaciais (McNamara et al., 1989). Tal forma de "agrupamento semântico" pode ter efeitos na memorização de localizações espaciais (Hirtle \& Mascolo, 1986). As conexões entre significados sociais e localização espacial parecem ampliar a capacidade do ambiente em informar agentes. As pessoas podem construir instruções sobre eventos no ambiente de forma indexada (Glenberg \& Robertson, 1999). Isso nos permite construir inferências - digamos, quando tentamos identificar uma rua provável onde podemos encontrar certa atividade.

Ao perceber um lugar ou edificação, percebemos não apenas sua forma, mas também a informação potencial envolvida nela (Haken \& Portugali, 2015). Consequentemente, atividades diversas numa área urbana são associadas a mais oportunidades de ação (Couclelis et al., 1987), uma forma de sinergia espacialmente manifesta na forma de proximidade e agrupamentos em categorias. Os aspectos do ambiente construído que codificam informação 2 permitem um entendimento relacional de seus conteúdos. As adjacências de diferentes conteúdos semânticos podem criar complementaridades do ponto de vista dos agentes em seus esforços para realizar e coordenar suas ações. As pessoas podem reconhecer o significado de uma atividade nos traços deixados por suas ações e associar esses traços ao seu ambiente urbano. Assim, o espaço não apenas representa a atividade: ele é apropriado e, como tal, carregado de significados. 0 espaço semântico encontra um nível de diferenciação semelhante a categorias de ações, porque compartilham a mesma natureza informacional. A informação semântica torna o espaço endógeno à ação, levando a um enorme aumento nas possibilidades combinatórias da interação (Netto et al., 2018).

Representações dificilmente capturariam a pluralidade de significados subjetivos no espaço. Entretanto, podemos tratar metodologicamente os diferentes significados coletivamente codificados e decodificados no espaço urbano. Fazemos isso através de mapas semânticos (Tversky, 1993). Mapas semânticos podem representar qualquer forma de conteúdo social no espaço urbano, desde interações em locais de atividade até encontros no espaço público. Para efeito de operacionalização metodológica, podemos escolher categorias clássicas em estudos urbanos, como os usos do solo variando de praças públicas a edifícios residenciais, para realizar análises de áreas urbanas (Figura 10, esquerda). A informação 2 envolve produção de significado em qualquer lugar do espaço construído, público ou privado, edificado ou aberto, mas para efeito de simplificação, focaremos primeiramente naqueles associados a edificações. A informação semântica pode ser medida como níveis de diversidade de conteúdos sociais, medindo a distribuição do uso do solo pela frequência de cada tipo de atividade na área.

A aparente contradição entre informação ambiental 1 física (reduzida à regularidade) e informação ambiental 2 semântica (reduzida à diversidade de conteúdos) é resolvida empiricamente no sentido em que operam em níveis diferentes de materialidade: num caso, no jogo de previsibilidades a nível do espaço físico, e noutro, a distribuição de conteúdos de informação diversos e concentrados em certas áreas e ruas, a nível do espaço semântico. Entretanto, ambas as camadas de informação ambiental envolvem diferenças, estruturas e padrões que precisam ser capturados, uma vez que tenhamos recursos metodológicos mais complexos e próximos à realidade.

A análise gráfica de um estudo piloto que desenvolvemos com algoritmos preparados por Edgardo Brigatti envolvendo usos do solo reais e uma distribuição fictícia gerada por Caio Cacholas em Porto Alegre (Figura 10, direita) mostra pontos de alta diversidade em ambos os mapas, correspondendo a interfaces locais e potencial complementaridade, tornando-a potencialmente atraente para mais pessoas. Esta técnica pode ser ampliada de forma a medir o efeito da concentração, especialização e complementaridade entre atividades urbanas, e aplicada em diferentes situações e contextos urbanos. 

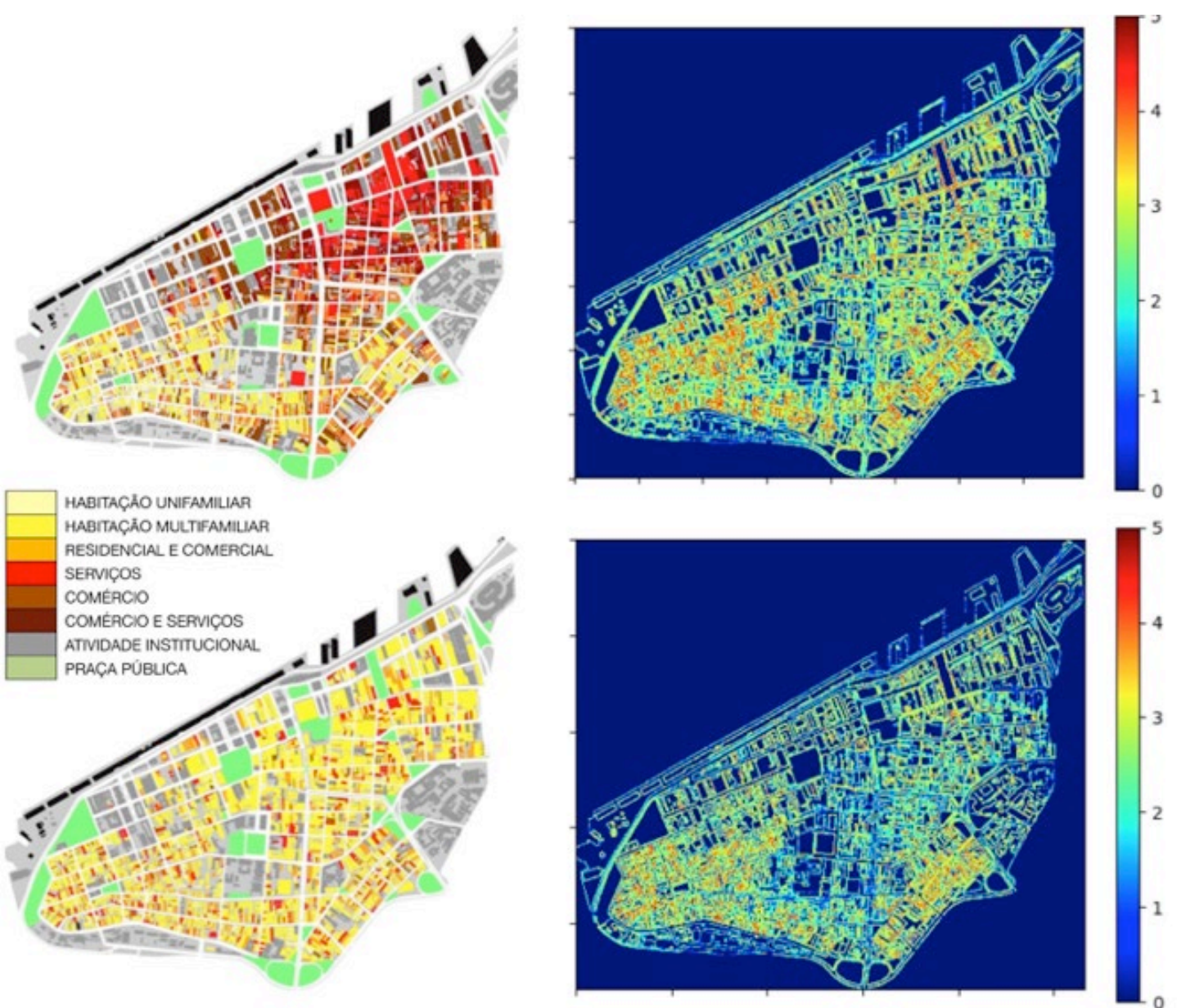

Figura 10 - Mapas semânticos: distribuições real (superior) e aleatória (inferior) de atividades no centro de Porto Alegre, à esquerda, com os valores correspondentes de informação 2 à direita. Fonte: mapa de uso do solo (distribuição real) de Maraschin (2014); distribuição aleatória de Caio Cacholas e análise quantitativa de Edgardo Brigatti em Netto et al. (2018).

\section{Informação 3: as interações}

A informação 3 é aquela criada pelas pessoas em suas mentes e trocada em suas comunicações a partir do modo como usam as informações ambientais 1 e 2 . Esse conceito tem forte relação com o conceito de "enação" de Varela et al. (1991). As abordagens à enação evoluíram em oposição ao cognitivismo computacional e rejeitam ver a mente apenas respondendo a estímulos ambientais (Di Paolo et al., 2010). Em vez disso, evocam como as pessoas guiam suas ações em situações concretas. A enação envolve (i) a percepção na ação; e (ii) estruturas cognitivas emergentes de padrões sensório-motores recorrentes que permitem que a ação seja perceptivamente guiada (Varela et al., 1991). Essa leitura se refere a paradigmas emergentes baseados em "incorporação", "situacionismo" e a relevância da cognição para a ação (Wilson, 2002; Stewart et al., 2010). A interação com o ambiente físico e social traz diferenças para a cognição e vice-versa (Varela et al., 1991; cf. Hutchins, 1995), num acoplamento entre o agente e o ambiente: nossas entradas sensoriais do ambiente guiam nossas ações e nossas ações modificam nossos retornos sensoriais e o próprio ambiente, em ciclos de percepção-ação. A interação social é emblemática na pesquisa da enação, vista como "construção de sentido participativo mútuo", envolvendo o surgimento de papéis, valores, disposições para agir e significados (Varela et al., 1991).

Neste ponto, chegamos a um aspecto fundamental da enação: como a coordenação entre as pessoas emerge. Só há comunicação se as interações mediadas por signos entre as pessoas resultam na coordenação de suas ações (Stewart et al., 2010). 


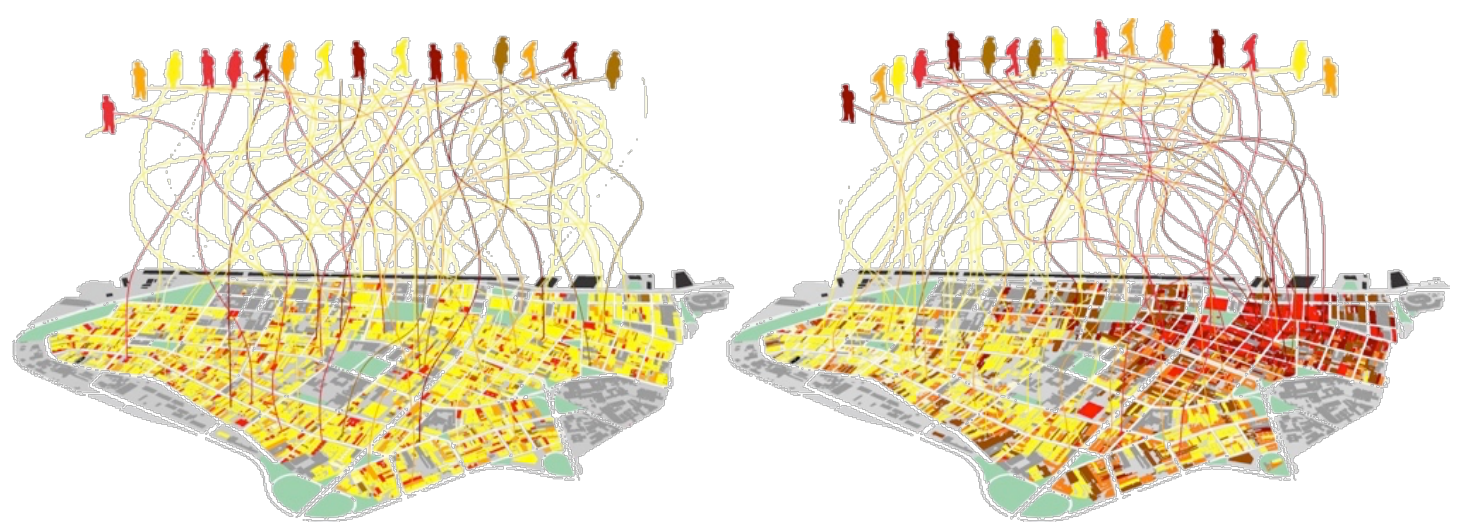

Figura 11 - Ações convergindo em distribuição aleatória simulada (esquerda) e com padrão real (direita): uma distribuição com padrão reconhecível pode intensificar a coordenação das ações. Fonte: Vinicius M. Netto e Caio Cacholas em Netto et al. (2018).

Como o papel do ambiente construído na cooperação envolve um número enorme de fatores que não podem ser inteiramente observados, desenvolvemos um método para simular situações concretas (Netto et al., 2017). Investigamos a hipótese de que a regularidade e hierarquia espacial a serem capturadas como informação 1 física, assim como a distribuição de conteúdos sociais contidas na informação 2 semântica aumentam o potencial de interações capturadas como informação 3 (Figura 11). Podemos avaliar as probabilidades de interações em ambientes virtuais. Uma maneira de fazer isso é quantificar a informação ambiental disponível para os agentes em suas ações.

Para analisar esse processo, usamos um modelo baseado em agentes (Agent Based Model, ABM) desenvolvido por João Meirelles baseado nas equações de Fabiano Ribeiro (Netto et al. 2017) para criar uma cidade capaz de representar os aspectos mínimos suficientes do que eu viria a chamar de informação ambiental 1 e 2, considerando agentes, tipos de ação, localizações e situações sociais (representadas por lugares de atividade) e parâmetros capazes de capturar aspectos do agente, como sua capacidade de reconhecer situações sociais, tomar decisões com base em suas orientações individuais e mudar suas ações e o ambiente semântico a sua volta. Os agentes selecionam os lugares de atividade mais similares a suas orientações e ações atuais em cada rodada, sendo então influenciados pelos lugares. Os agentes também podem influenciar lugares, mas estes mudam em ritmo mais lento. 0 modelo considera que agentes coevoluem junto a seu ambiente.

Este modelo é baseado em uma cidade unidimensional e circular, com restrições em termos de representatividade de cidades reais. Valores baixos de informação 3 indicarão que as ações têm quase a mesma probabilidade de acontecer, mostrando baixa coordenação entre pessoas, enquanto valores altos indicarão tendências de ação coletiva mais coordenada. A informação ambiental "capturaria" as pessoas: elas podem alinhar suas ações através dos conteúdos de informação urbana. Em termos práticos, isso significa cooperação e a criação de sistemas de interação. Em termos científicos, significa a corroboração da hipótese central da pesquisa em ambiente virtual (Figura 12). 

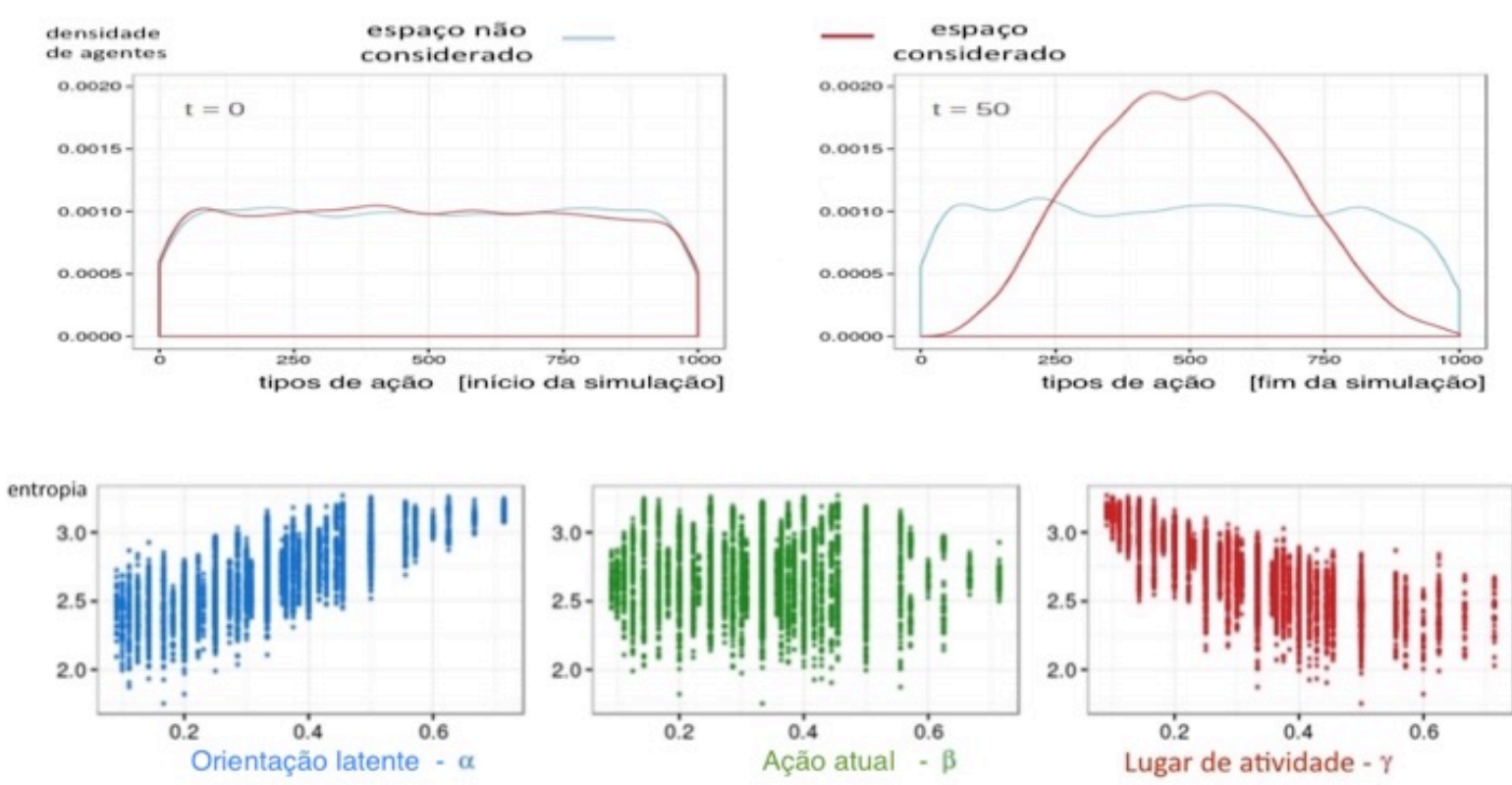

Figura 12 - Acima, histogramas de distribuição de probabilidade dos tipos de ação mostram altos níveis de entropia no início das simulações (esquerda) em dois tipos de cenários: a distância entre os locais de atividade não sendo considerada (linha azul) e a distância sendo considerada (linha vermelha). No final das simulações

(à direita), o tipo de cenário em que o espaço é materialmente ativo mostra convergência em torno de certos tipos de ação, indicando cooperação e redução da entropia. Abaixo, a importância de cada parâmetro: cada conjunto vertical de pontos representa um valor fixo para o parâmetro destacado, com os outros dois parâmetros assumindo todas as combinações possíveis dentro da faixa testada. Cada ponto corresponde ao valor da entropia. Fonte: João Meirelles em Netto et al. (2017).

\section{Notas finais: da forma urbana à cidade como informação}

O modelo de comportamento urbano e entropia social vem agora sendo expandido com meus colegas Fabiano Ribeiro, Caio Cacholas e Lucas Martello na forma de representações bidimensionais detalhadas de cidades reais. A evolução da abordagem visa verificar o quanto o espaço urbano (informação 1 e 2) gera diferenças entre possibilidades de interação (informação 3), de menos para mais prováveis, aumentando as chances de certas escolhas de atividades urbanas e ações sociais serem realizadas pelos agentes. Com foco em situações reais, a pesquisa está produzindo um banco de dados de cidades de diferentes culturas e regiões do mundo, hoje com mais de 40 cidades, analisadas do ponto de vista da informação.

Sumarizando nossos objetivos de contribuição em seus aspectos mais práticos e próximos à experiência urbana, a pesquisa investiga o papel da informação ambiental no acesso cotidiano a oportunidades urbanas relacionadas a padrões de localização e mobilidade e vê o acesso à informação ambiental como um fator potencial de desigualdade e justiça socioespacial.

Em seus aspectos mais amplos, a pesquisa investiga o papel da informação ambiental na cooperação entre agentes e em como estes se organizam socialmente. Uma dimensão aberta por esta abordagem é entender como populações lidam com sua própria tendência à entropia, criando formas de coordenar ações e orientações individuais a partir do ambiente construído.

Para tanto, a abordagem vem desenvolvendo modelos computacionais de comportamento das pessoas no espaço urbano e medidas de informação e entropia latentes nas estruturas físicas e semânticas das cidades. Essas medidas permitem examinar cidades com grande grau de detalhe, como detectar diferenças nos padrões de ocupação, densidade e uso do solo. Permitem ainda avaliar o impacto de diferentes ambientes urbanos sobre comportamentos, em sua capacidade de dar suporte às ações e à cooperação entre seus habitantes. No andamento desta pesquisa, essas relações poderão ainda ser 
entendidas através do exame de correlações entre medidas de informação ambiental, entropia social e indicadores como os de qualidade de vida, renda, diversidade no uso da terra, mobilidade e percepção de segurança. Finalmente, essa abordagem vai permitir interpretar características da forma urbana como "assinaturas de informação" específicas para cada ambiente construído, respondendo o que chamamos com Brigatti e Cacholas de "hipótese cultural" (Netto et al., 2020c): a ideia de que diferentes culturas e regiões em diferentes partes do mundo encontram maneiras diferentes de ordenar seus espaços.

\section{Referências}

Aguiar, D. (2010). Alma espacial: corpo e o movimento na arquitetura. Porto Alegre: Editora UFRGS.

Alexander, C. (1965a). A city is not a tree. Part I. The Architectural Forum, 122(1), 58-62.

Alexander, C. (1965b). A city is not a tree. Part II. The Architectural Forum, 122(2), 58-62.

Amorim, L., Barros, M., Fo., \& Cruz, D. (2014). Urban texture and space configuration: an essay on integrating sociospatial analytical techniques. Cities, 39, 58-67. http://dx.doi.org/10.1016/j.cities.2014.02.001.

Angelo, H., \& Vormann, B. (2018). Long waves of urban reform: putting the smart city in its place. City, 22(5-6), 782-800. http://dx.doi.org/10.1080/13604813.2018.1549850.

Banino, A., Barry, C., Uria, B., Blundell, C., Lillicrap, T., Mirowski, P., Pritzel, A., Chadwick, M. J., Degris, T., Modayil, J., Wayne, G., Soyer, H., Viola, F., Zhang, B., Goroshin, R., Rabinowitz, N., Pascanu, R., Beattie, C., Petersen, S., Sadik, A., Gaffney, S., King, H., Kavukcuoglu, K., Hassabis, D., Hadsell, R., \& Kumaran, D. (2018). Vector-based navigation using grid-like representations in artificial agents. Nature, 557(7705), 429-433. http://dx.doi.org/10.1038/s41586-0180102-6. PMid:29743670.

Bateson, G. (1972). Steps to an ecology of mind. London: Jason Aronson Inc.

Batty, M. (2005). Cities and complexity: understanding cities with cellular automata, agent-based models, and fractals. Cambridge: The MIT Press.

Bellmund, J., Deuker, L., Schröder, T., \& Doeller, C. (2016). Grid-cell representations in mental Simulation. eLife, 5 , e17089. http://dx.doi.org/10.7554/eLife.17089. PMid:27572056.

Binder, C. R., Wyss, R., \& Massaro, E. (2020). Sustainability assessment of urban systems. Cambridge: Cambridge University Press. http://dx.doi.org/10.1017/9781108574334.

Boeing, G. (2019). Spatial information and the legibility of urban form: big data in urban morphology. International Journal of Information Management, 102013. No prelo. http://dx.doi.org/10.1016/j.ijinfomgt.2019.09.009.

Boltzmann, L. (2015). On the relationship between the second fundamental theorem of the mechanical theory of heat and probability calculations regarding the conditions for thermal equilibrium. Entropy, 17(4), 1971-2009. http://dx.doi.org/10.3390/e17041971.

Caduff, D., \& Timpf, S. (2008). On the assessment of landmark salience for human navigation. Cognitive Processing, 9(4), 249-267. http://dx.doi.org/10.1007/s10339-007-0199-2. PMid:17999102.

Clark, A., \& Chalmers, D. (1998). The extended mind. Analysis, 58(1), 7-19.

http://dx.doi.org/10.1093/analys/58.1.7.

Clark, A. (1997). Being there: putting brain, body, and world together again. Cambridge: The MIT Press.

Couclelis, H., Golledge, R., Gale, N., \& Tobler, W. (1987). Exploring the anchorpoint hypothesis of spatial cognition. Journal of Environmental Psychology, 7(2), 99-122. http://dx.doi.org/10.1016/S0272-4944(87)80020-8.

Davies, P., \& Gregersen, N. H. (Eds.). (2010). Information and the nature of reality: from physics to metaphysics. Cambridge: Cambridge University Press.

Devlin, K. (1991). Logic and information. Cambridge: Cambridge University Press. 
Di Paolo, E. D., Rohde, M., \& Jaegher, D. (2010). Horizons for the enactive mind: values, social interaction, and play. In J. Stewart, O. Gapenne, \& E. D. Paolo (Eds.), Enaction: toward a new paradigm for cognitive science (pp. 33-88). Cambridge: The MIT Press. http://dx.doi.org/10.7551/mitpress/9780262014601.003.0003.

Doeller, C. F., Barry, C., \& Burgess, N. (2010). Evidence for grid cells in a human memory network. Nature, 463(7281), 657-661. http://dx.doi.org/10.1038/nature08704. PMid:20090680.

Dretske, F. I. (1981). Knowledge and the flow of information. Cambridge: The MIT Press.

Ekstrom, A. D., Spiers, H. J., Bohbot, V. D., \& Rosenbaum, R. S. (2018). Human spatial navigation. Princeton: Princeton University Press. http://dx.doi.org/10.2307/j.ctvc773wg.

Evans-Cowley, J., \& Griffin, G. (2012). Microparticipation with social media for community engagement in transportation planning. Transportation Research Record: Journal of the Transportation Research Board, 2307(1), 90-98. http://dx.doi.org/10.3141/2307-10.

Figueiredo, L., \& Ortiz-Chao, C. (2015). Análise configuracional do ambiente construído: lotes, edifícios e uso do solo. In Anais do XVI ENANPUR. São Paulo: ANPUR.

Garlandini, S., \& Fabrikant, S. I. (2009). Evaluating the effectiveness and efficiency of visual variables for geographic information visualization. In International Conference on Spatial Information Theory (Vol. 5756, pp. 195-211). New York: Springer. http://dx.doi.org/10.1007/978-3-642-03832-7_12.

Glenberg, A. M., \& Robertson, D. A. (1999). Indexical understanding of instructions. Discourse Processes, 28(1), 126. http://dx.doi.org/10.1080/01638539909545067.

Hafting, T., Fyhn, M., Molden, S., Moser, M. B., \& Moser, E. I. (2005). Microstructure of a spatial map in the entorhinal cortex. Nature, 436(7052), 801-806. http://dx.doi.org/10.1038/nature03721. PMid:15965463.

Haken, H., \& Portugali, J. (2015). Information adaptation: the interplay between shannon information and semantic information in cognition. New York: Springer.

Hidalgo, C. (2015). Why information grows: the evolution of order, from atoms to economies. New York: Basic Books.

Hillier, B., \& Hanson, J. (1984). The social logic of space. Cambridge: Cambridge University Press. http://dx.doi.org/10.1017/CB09780511597237.

Hirtle, S. C., \& Mascolo, M. F. (1986). Effect of semantic clustering on the memory of spatial locations. Journal of Experimental Psychology. Learning, Memory, and Cognition, 12(2), 182-189. http://dx.doi.org/10.1037/02787393.12.2.182. PMid:2939175.

Holanda, F. (2002). O espaço de exceção. Brasília: Editora Universidade de Brasília.

Hutchins, E. (1995). Cognition in the wild. Cambridge: The MIT Press.

Jacobs, J. (1969). The economy of cities. New York: Random House.

Kitchin, R. (2016). The ethics of smart cities and urban science. Philosophical Transactions of the Royal Society A: Mathematical, Physical and Engineering Sciences, 374(2083), 20160115.

http://dx.doi.org/10.1098/rsta.2016.0115. PMid:28336794.

Krafta, R. (2014). Notas de morfologia urbana. Porto Alegre: Editora UFRGS.

Larrañaga, A., Ribeiro, J. L., \& Cybis, H. (2009). Fatores que afetam as decisões individuais de realizar viagens a pé: estudo qualitativo. Revista Transportes., 17(2), 16-26. http://dx.doi.org/10.14295/transportes.v17i2.355.

Lynch, K. (1960). The image of the city. Cambridge: The MIT Press.

Maraschin, C. (2014). Dinâmica e resiliência das áreas comerciais: uma abordagem configuracional em Porto Alegre, RS (Projeto de Pesquisa). Porto Alegre: UFRGS, PROPUR.

Martin, L., \& March, L. (1972). Urban space and structures. Cambridge: University Press. 
McNamara, T. P., Halpin, J. A., \& Hardy, J. K. (1992). The representation and integration in memory of spatial and nonspatial information. Memory \& Cognition, 20(5), 519-532. http://dx.doi.org/10.3758/BF03199584. PMid:1453969.

McNamara, T. P., Hardy, J. K., \& Hirtle, S. C. (1989). Subjective hierarchies in spatial memory. Journal of Experimental Psychology. Learning, Memory, and Cognition, 15(2), 211-227. http://dx.doi.org/10.1037/02787393.15.2.211. PMid:2522511.

Medeiros, V. (2013). Urbis brasiliae: o labirinto das cidades brasileiras. Brasília: Editora Universidade de Brasília.

Netto, V. M., Fiszon, M., Moreira, M. C., \& Moraes, I. (2020a). Pesquisa urbana no Brasil: um panorama inicial [parte 2]. Arquitextos, 20, 238.06.

Netto, V. M., Meirelles, J., \& Ribeiro, F. L. (2020b). Cities and entropy: assessing urban sustainability as a problem of coordination. In C. Binder, R. Wyss, \& E. Massaro (Eds.), Sustainability assessment of urban systems (pp. 438-459). Cambridge: Cambridge University Press. http://dx.doi.org/10.1017/9781108574334.020.

Netto, V. M., Brigatti, E., \& Cacholas, C. (2020c). From form to information: analysing built environments in different spatial cultures. arXiv. https://arxiv.org/abs/2006.13897.

Netto, V. M., Brigatti, E., Cacholas, C., \& Aleixo, V. (2019). Assessing spatial information in physical environments. In Proceedings of the 14th International Conference on Spatial Information Theory (COSIT 2019) (Vol. 142). Regensburg, Germany: Dagstuhl Publishing.

Netto, V. M., Brigatti, E., Meirelles, J., Ribeiro, F. L., Pace, B., Cacholas, C., \& Sanches, P. (2018). Cities, from information to interaction. Entropy, 20(11), 834. http://dx.doi.org/10.3390/e20110834.

Netto, V. M., Meirelles, J., \& Ribeiro, F. (2017). Social interaction and the city: the effect of space on the reduction of entropy. Complexity, 2017, 1-16. http://dx.doi.org/10.1155/2017/6182503.

O'Keefe, J., \& Dostrovsky, J. (1971). The hippocampus as a spatial map: preliminary evidence from unit activity in the freely-moving rat. Brain Research, 34(1), 171-175. http://dx.doi.org/10.1016/0006-8993(71)90358-1. PMid:5124915.

Parker, E. (1974). Information and society. In Proceedings of a Conference on the Needs of Occupational, Ethnic, and other Groups in the United States (pp. 9-50). Washington: ERIC.

Passini, R. (1992). Wayfinding in architecture. New York: Wiley.

Pereira Costa, S., \& Teixeira, M. C. V. (2014). The study of urban form in Brazil. Urban Morphology, 18(2), $119-127$.

Prigogine, I., \& Stengers, I. (1984). Order out of chaos: man's new dialogue with nature. New York: Bantam Books.

Rapoport, A. (1982). The meaning of the built environment. Thousand Oaks: Sage.

Rosch, E. (1978). Principles of categorization. In Roach, E., \& Lloyd, B. B., (Eds.), Cognition and categorization (pp. 27-48.). Hillsdale: Lawrence Erbaum Associates.

Rosenholtz, R., Li, Y., \& Nakano, L. (2007). Measuring visual clutter. Journal of Vision, 7(2), 1-22. http://dx.doi.org/10.1167/7.2.17. PMid:18217832.

Schrödinger, E. (1944). What is life? The physical aspect of the living cell and mind. Cambridge: Cambridge University Press.

Shannon, C. E. (1948). A mathematical theory of communication. The Bell System Technical Journal, 27(4), 623-656. http://dx.doi.org/10.1002/j.1538-7305.1948.tb00917.x.

Stewart, J., Stewart, J. R., Gapenne, O., \& Paolo, E. A. D. (2010). Enaction: toward a new paradigm for cognitive science. Cambridge: The MIT Press. http://dx.doi.org/10.7551/mitpress/9780262014601.001.0001.

Taylor, H. A., Wang, Q., Gagnon, S. A., Maddox, K. B., \& Brunyé, T. T. (2011). The social connection in mental representations of space: explicit and implicit evidence. In M. Egenhofer, N. Giudice, R. Moratz, \& M. Worboys (Eds.), International Conference on Spatial Information Theory (pp. 231-244). Berlin: Springer.

http://dx.doi.org/10.1007/978-3-642-23196-4_13. 
Tversky, B. (1993). Cognitive maps, cognitive collages, and spatial mental models. In I. Campari, \& A. Frank (Eds.), European Conference on Spatial Information Theory (pp. 14-24), New York: Springer, .

http://dx.doi.org/10.1007/3-540-57207-4_2.

Varela, F. J., Rosch, E., \& Thompson, E. (1991). The embodied mind: cognitive science and human experience. Cambridge: The MIT Press. http://dx.doi.org/10.7551/mitpress/6730.001.0001.

Vygotsky, L. (1978). Mind in society: the development of higher psychological processes. Cambridge: Harvard University Press.

Weaver, W. (1949). Recent contributions to the mathematical theory of communication. In C. E. Shannon, \& W. Weaver (Eds.), The mathematical theory of communication (pp. 1-28). Champaign: The Illinois University Press.

Wilson, M. (2002). Six views of embodied cognition. Psychonomic Bulletin \& Review, 9(4), 625-636. http://dx.doi.org/10.3758/BF03196322. PMid:12613670.

Editores convidados: Vitor Oliveira (Universidade do Porto, Portugal) e Bruno Zaitter (PUCPR, Brasil)

Recebido: Set. 04, 2019

Aprovado: Maio 19, 2020 